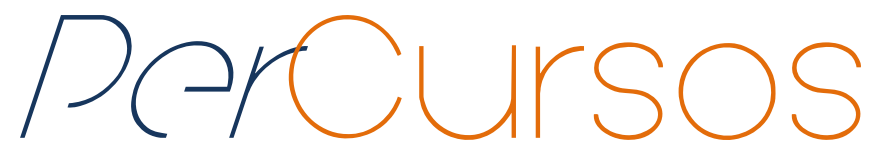

\title{
A guerra de baixa intensidade contras as comunidades zapatistas de Chiapas-México
}

\section{Resumo}

Este texto é um fragmento da minha tese de doutorado, e nele é abordado um dos aspectos específicos de um dos termos da relação que foi definida como eixo central da tese, a saber: a tensão entre guerra e política no conflito político-militar no sudeste de Chiapas-México contra as comunidades rebeldes autônomas zapatistas. Esta é a relação que sugiro como chave de leitura para entender dito conflito. Dessa maneira, este texto explora a redefinição da guerra elaborada pelo governo federal mexicano e o estadual de Chiapas contra as comunidades zapatistas rebeldes em resistência, no que se conhece como guerra de baixa intensidade $(\mathrm{GBI})$. Tal reconceituação e reposicionamento político-militar do Estado mexicano (e setores que o apoiam) é uma reação à redefinição de luta social proposta anteriormente pelas/os Zapatistas, no que se conhece como guerra de redes sociais.

Palavras-chave: Zapatismo; Guerra de Baixa Intensidade; Política; Resistência.

\author{
Leandro Marcelo Cisneros \\ Doutor em Ciências Humanas \\ Universidade Federal de Santa \\ Catarina - UFSC. Professor no \\ Centro Universitário de \\ Brusque/SC - UNIFEBE. \\ Brasil \\ leocis69@gmail.com
}




\title{
Low-intensity warfare against the Zapatista communities of Chiapas-Mexico
}

\begin{abstract}
This text is a fragment of my doctoral thesis, and it is an approximation of one of the specific aspects of the terms of the relationship that has been defined as the centerpiece of the thesis, namely, the tension between war and politics in the politic-military conflict in Southeast Chiapas-Mexico against the Zapatista autonomous rebel communities. This is the relationship that I suggest reading as key to understanding said conflict. Thus, this paper explores the redefinition of war elaborated by the Mexican federal government and the state government of Chiapas against the Zapatista rebels communities in resistance, in what is known as low-intensity warfare. Such reconceptualization and political-military repositioning of the Mexican state (and sectors that support it) is a reaction to the redefinition of social struggle proposed previously by the Zapatistas, in what is known as war social networks.
\end{abstract}

Keywords: Zapatism; Low-Intensity Warfare; Politics; Resistance.

\section{Para citar este artigo:}

CISNEROS, Leandro Marcelo. A guerra de baixa intensidade contras as comunidades zapatistas de Chiapas-México. Revista PerCursos. Florianópolis, v. 16, n.32, p. 58 - 84, set./dez. 2015.

DOI: $\mathbf{1 0 . 5 9 6 5 / 1 9 8 4 7 2 4 6 1 6 3 2 2 0 1 5 0 5 8}$

http://dx.doi.org/10.5965/1984724616322015058 


\section{Contextualização do conflito político-militar em Chiapas}

O exército mexicano trilhou outros caminhos, antes de chegar à definição dessa estratégia, que é a que atualmente se denomina como guerra de baixa intensidade (GBI). Nos primeiros dias de combate de janeiro de 1994, em relação à quantidade de efetivos militares e armamento enviado para a zona de conflito, a primeira resposta foi a de retaliar com todas as forças possíveis, inspirados, talvez, na crença de que uma única ação contundente e enérgica seria o suficiente para derrotar os índios ou, em todo caso, pelo menos amedrontá-los o suficiente, como para fazê-los desistir. Assim o afirma Ronfeldt (et al) $)^{1}$ :

[...] Within days, the number of army troops in Chiapas expanded from $\mathbf{2 , 0 0 0}$ to about 12,000. Air and ground attacks were conducted in rebelheld areas [...] The army eagerly wanted to crush the rebellion forcefully, continuing along the lines it had established in the opening two weeks of the conflict [...] Although the government and the army initially responded in a traditional, heavy-handed manner to the EZLN's insurrection, they have not responded idly or unthinkingly since then to this seminal case of social netwar (RONFELDT et al, 1998, p. 3, 78 e 80). Grifos nossos.

Assim, inicialmente predominava a forte e ostensiva presença de efetivos militares, desenvolvendo uma guerra com armas de fogo e também uma guerra psicológica, através de ações terroristas, como foram os ataques a populações civis, indiscriminadas detenções, torturas, sequestros, desaparecimentos, execuções sumárias. Sem esquecer as perseguições, ameaças, amedrontamentos que, via de regra, eram o procedimento com qualquer um/a que tivesse aspecto de zapatista (Ibid, p. 2; MUÑOZ RAMÍREZ, 2003, p. 88, 90, CDHFBC, 1999). Isto é, o governo e o exército reagiram inicialmente segundo as cartilhas que orientam como conter uma insurgência tradicional (MONROY GÓMEZ; CUENCA, 1994).

No entanto, logo após o início do confronto franco, o exército federal percebeu as dificuldades táticas para cumprir com o projeto original de identificar-isolar-esmagar o

\footnotetext{
1 Leyva Solano (2009) comenta que D. Ronfeldt, J. Arquilla, G. E. Fuller e M. Fuller, do serviço de inteligência dos EUA, no livro The Zapatistas Social Netwar in México (1998), foram os primeiros a escrever sobre este tipo de guerra.
} 
inimigo. Entre elas, a clássica tática guerrilheira de confrontar o exército regular com as altas dificuldades do terreno selvático de montanha e o desconhecimento do terreno. A isto também se somou a quase imediata reação da sociedade civil nacional e internacional exercendo grande pressão em prol do respeito dos direitos humanos, levando o governo e o exército a reavaliar e redefinir sua estratégia, pois entenderam que havia a necessidade de readequação a uma nova situação de guerra que tinha novos aspectos. Assim foi que o exército mexicano teve que "responder a la red con una política antirredes de guerra" (LEYVA SOLANO, 2009, p. 118) ou, em outras palavras, "beginning in 1994 the federal government, its national security apparatus, and the military had to try to transform themselves to respond to this social netwar" (RONFELDT et al. 1998, p. 82).

Esse trabalho de Ronfeldt (et al) recomenda tanto ao governo como ao exército mexicanos a abandonar os velhos métodos de contrainsurgência de linha dura, ao mesmo tempo que tem advertido ao exército dos EUA sobre a necessidade de ser cauteloso numa associação demasiado estreita com um exército que sempre tem essa estratégia como uma das cartas possíveis para o jogo e que, além do mais, tem uma longa tradição de sempre se valer dela (Ibid, p. 31, 107 e 111). Contudo, essa tem sido sempre uma das estratégias constantes, só que com certa intermitência, tem sido empregada com mais ou menos protagonismo. A questão é que para fins de 1999, 30\% das forças do exército mexicano estavam apostas em Chiapas (LEYVA SOLANO, 2009, p. 119).

Resumindo, aos poucos estamos especificando e detalhando as características singulares concretas desta guerra, neste território, entre esses protagonistas (mencionando apenas os mais destacados), mas isso não deve nos distrair ao ponto de nos fazer perder a visão panorâmica, a visão de conjunto. Não podemos esquecer que esse é apenas um capítulo dentro de uma guerra ainda maior, mais antiga, de mais longo fôlego, mais abrangente. Referimo-nos àquela que o Subcomandante Insurgente Marcos (1997) chama de IV Guerra Mundial, isto é, uma guerra que, na América Latina já leva mais de meio milênio, que é de dimensões mundiais e que tem como um dos seus principais objetivos a guerra pelo domínio sobre os recursos.

Como já comentamos, o Capítulo Chiapas dessa guerra começou como iniciaram outros capítulos, sendo uma guerra de alta intensidade (GAl), como a que não há muito 
levou à frente os EUA contra o Iraque, mas que no caso específico do Zapatismo em Chiapas, deveu ser revisada e reformulada para o que se começou a chamar a guerra de baixa intensidade (GBI) (FAJARDO CAMACHO, 2011, p. 56).

\section{O que é a guerra de baixa intensidade?}

Para caracterizar de forma mais específica a GBI, a seguir, apresento um breve histórico sobre as origens dessa estratégia².

Na década de 1960, no governo Kennedy, após o fracasso estadunidense na invasão a Cuba, em 1961, se iniciam mudanças nas estratégias militares, denominada reação flexível, com o objetivo de dar uma resposta mais eficiente aos avanços da União Soviética na Europa, Ásia, China e Vietnã. Basicamente, a ideia-eixo daquela redefinição foi a de interferir em assuntos do interesse dos EUA, mas sem comprometer diretamente as forças armadas estadunidenses, embora esse país estivesse de prontidão para oferecer apoio econômico e, se necessário, militar a seus aliados, também incluindo fornecer treinamento específico a forças contrainsurgentes, entre outras ações nessa direção.

No governo Nixon (1969-1974) foi avaliado que o alerta de maior risco para os interesses dos EUA, já não era a URSS ou China, mas, sim, os levantamentos acontecidos nos países pobres do Terceiro Mundo ${ }^{3}$. E é a partir dessa preocupação que surge um novo conceito estratégico, a contrainsurgência, que basicamente se pensou como estratégia para enfrentar o novo tipo de guerra de guerrilhas, acionando um repertório mais amplo e estrategicamente articulado entre recursos econômicos, psicológicos, sociais, diplomáticos, militares e paramilitares.

No governo Carter (1977-1981), após a derrota no Vietnã, o sucesso da Revolução Sandinista na Nicarágua, as complicações em El Salvador, os movimentos sociais e

\footnotetext{
${ }^{2}$ Para tal, me apoio, principalmente, no trabalho de Fajardo Camacho (Ibid, p. 57-58), complementando com outras leituras. Por sua vez, a autora esclarece que toma os dados do livro La guerra de baja intensidade en México de Martha López Astrain, 1996.

3 A autora cita do artigo La guerra de baja intensidad de Francisco Pineda na Revista Chiapas, que no período entre o pós-Segunda Guerra Mundial e final dos anos de 1960, no Terceiro Mundo aconteceram 120 guerras, deixando mais de 10 milhões de mortos.
} 
políticos de Moçambique, Angola, Camboja e Etiópia, a invasão da URSS ao Afeganistão, a retirada dos EUA da Angola e Indochina, é avaliada como necessária a criação de uma estrutura de forças militares especiais estadunidenses para intervenções rápidas no Terceiro Mundo.

Essa estrutura será confirmada e consolidada dentro do exército dos EUA no governo Reagan (1981-1989), Entre outros fatores, possivelmente porque a opinião pública tinha uma visão negativa da administração anterior de Carter, já que a considerou prejudicial para os interesses nacionais. Essa forte crítica do povo estadunidense se traduzia numa crise de credibilidade e um estancamento institucional, ocasionando uma perda de prestígio dos EUA (SCHIAVONE, 2003, p. 2).

Perante essa situação, a gestão Reagan, que tinha o signo da mudança (na direção de uma reação conservadora), iniciava com o propósito de “devolver a los EEUU su lugar como potencia hegemónica mundial y para ello adoptó una estrategia ofensiva, tanto en lo ideológico como en lo geoestratégico" (SCHIAVONE, 2003, p. 3). Com essa inspiração é que surgiu o conceito estratégico de força de acionamento rápido (rapid deployment force) que priorizava o aspecto político do conflito, mais do que o militar, articulando uma instrumentalização com os exércitos locais para que eles fossem os que saturassem o teatro de guerra e derrotas sem o inimigo. Assim foi como aconteceu na Guatemala, El Salvador e Nicarágua. Posteriormente, é nesse mesmo governo que a inteligência militar estadunidense desenvolve e implementa o conceito guerra de baixa intensidade ${ }^{4}$, se mostrando muito eficiente no cumprimento dos seus "objetivos de aislar, desgastar, dividir y desorganizar a los movimentos sociales que buscan el cambio social, económico y político, a través de provocar miedo, tensión, confusión y división entre familias y comunidades" (CDHFBC, 1999, p. 6). Isso foi o que funcionou eficazmente nos casos da Nicarágua, Moçambique e Afeganistão.

\footnotetext{
${ }^{4}$ No ano de 1985, o Pentágono iniciou o Projeto sobre a Guerra de Baixa Intensidade, que em 1986 já tinha resultado na publicação da obra Joint Low-Intensity Conflict Project Final Report. Em fevereiro de 1986 se cria o Comando Conjunto do Exército e a Força Aérea para a Guerra de Baixa Intensidade. Também ver SCHIAVONE, 2003, p. 2.
} 
A nova doutrina militar da GBI é um conceito de menor abrangência que o seu parente conhecido como iniciativa de defesa estratégica. A GBI surge como uma opção coerente para a contenção ativa no Terceiro Mundo, familiar com as pequenas guerras sujas contra países inimigos dos EUA e sua aplicação tática operativa se leva a cabo, principalmente, mediante as chamadas Forças de Operações Especiais (FOE). Essa nova doutrina inclui também a noção de contraterrorismo, que se baseia em ações terroristas encobertas, dado que se supõe que as ações terroristas são as armas fundamentais do inimigo contra objetivos estadunidenses (cf. LOZANO; BENÍTEZ MANAUT, 1986).

A GBI oferece uma gama muito ampla de atividades que não implicam, necessariamente, o acionamento de tropas e o emprego sistemático das forças armadas, o qual complica e amplia os modos de intervenção. Os fatores econômicos, psicológicos e políticos constituem partes vitais da trama estratégica e implicam a coordenação de tropas, a implementação das denominadas operações especiais (atividades clandestinas paramilitares) e o protagonismo dos sistemas de inteligência, as estruturas diplomáticas e os desenvolvimentos logísticos. Em definitivo, um complexo conjunto de atividades não convencionais que, centradas no uso da força, coordenam as tarefas de grupos e organismos de natureza diversa, aplicados à luta ideológica (SCHIAVONE, 2003, p. 5). Nas palavras da equipe do Pentágono, que apresentou o projeto em 1986:

[... ] Low-intensity conflict: A limited politico-military struggle to achieve political, social, economic, or psychological objectives. It is often protracted and ranges from diplomatic, economic, and psychosocial pressures through terrorism and insurgency. Low-intensity conflict is generally confined to a geographic area and is often characterized by constraints on the weaponry, tactics, and level of violence (US-Army, 1986, p. Glossary-6). Grifos nossos.

Como vemos, a doutrina da GBI pressupõe que o combate não é apenas no plano militar e que, para ter sucesso, o planejamento deve atingir todos esses outros planos. Por outro lado, também sugere a versatilidade, variabilidade, flexibilidade e criatividade no uso de recursos, que devem responder apenas a um fim: derrotar o inimigo. Também frisa a necessidade de restringir o armamento e os níveis de violência. Isso é assim, se o 
entendemos da seguinte maneira, restrição de armamento, significa menor quantidade numérica, sim, mas de maior eficácia técnico-tecnológica e tático-estratégica. Isto é, restrição em termos relativos. E o mesmo podemos dizer a respeito dos níveis de violência, pois isso é assim, se entendemos que diminuem a quantidade e duração de confrontos armados tradicionais, como era até 1945, mas se avaliamos os impactos e estragos nos níveis social, econômico, político e psicológico, essa restrição também é bem relativa. Finalmente, está abertamente declarada a necessária ausência de escrúpulos para atingir o único fim que importa: a vitória total e duradoura que garanta a posição dominante e hegemônica dos EUA e seus aliados.

É por isso que a eficácia da GBI tem sido avaliada como muito positiva em vários aspectos fundamentais de um confronto. Primeiramente, não promovendo a mobilização aberta de grandes contingentes de efetivos, evita o envolvimento público direto da imagem dos EUA nas ações contrainsurgentes; também fica muito menos exposta a imagem do governo local do país em questão; sendo que unidades operacionais menores, altamente qualificadas com treinamento específico e intensivo, se mostraram muito mais eficazes para o cumprimento dos objetivos militares (contenção, identificação, desarticulação, imobilização e até eliminação do inimigo). Como se esses benefícios não fossem já uma ótima avaliação, esse tipo de guerra, além de um baixo custo para a imagem política do governo local e dos EUA, é uma estratégia mais eficiente economicamente, isto é, melhores e mais rápidos resultados a um custo menor.

Nesse sentido, concordamos com Schiavone, quando afirma que:

[...] las guerras posteriores a 1945 se han transformado, quebrando el modelo clausewitziano y acabando con la estructura de la guerra institucionalizada [... ] De alguna manera, esta doctrina [GBI] oficializó las transformaciones del conflicto bélico de la segunda post-guerra y estableció, por escrito, los nuevos parámetros de los enfrentamientos típicos de la época (SCHIAVONE, 2003, p. 1 e 7). Grifos nossos.

Até aqui, uma rápida reconstrução de como esse conceito evoluiu no pensamento militar nos contextos social e político que definiram sua necessidade. 


\section{A guerra de baixa intensidade no México}

Para além do seu aspecto técnico-militar, nos perguntamos o seguinte: o que significa que um exército como o mexicano, autorizado pelo governo federal, desenvolva uma GBI?

Primeiramente, é a aceitação explícita e sem discussão de uma política exterior intrusiva de parte dos EUA, ao ponto de permitir que esse governo estrangeiro interfira na pauta da agenda dos assuntos internos do governo mexicano. Isto, sob a justificativa de que combater esses conflitos é fundamental para proteger os interesses dos EUA.

Em declaração pública, o ex-presidente James Carter assim o expressava:

[... ] Let our position be absolutely clear: An attempt by any outside force to gain control of the Persian Gulf regions will be regarded as an assault on the vital interests of the United States of America. And such an assault will be repelled by any means necessary, including military force (CARTER, 1980). Grifos meus.

Esse parágrafo resume o que depois será conhecida como a Doutrina Carter, que tem balizado a política exterior dos EUA desde então.

Aceita essa perspectiva política, os objetivos principais são desenvolver ações de contrainsurgência, ou seja, derrotar movimentos de rebelião popular; ou ações de reversão, que significa depor governos revolucionários ou aqueles que não se ajustem à conformidade dos interesses estadunidenses; e ações de prevenção, isto significa ajudar governos aliados dos Estados Unidos a evitar sua desestabilização. O tipo de vitória que se busca com a estratégia da GBI não é apenas militar, mas uma vitória completa e duradoura, visando à eliminação efetiva da força política e moral da insurgência. Como já podemos concluir, o principal teatro de operações da GBI não é só México, mas todo o chamado Terceiro Mundo. (FAJARDO CAMACHO, 2011, p. 58-59). Embora, devemos destacar que o México tem um particular plus de importância geoestratégica para os 
EUA, devido à ampla fronteira compartilhada e sua abundância de recursos naturais e fartura de mão de obra, qualificada ou não, facilmente explorável a baixo custo.

\subsection{O aspecto militar da guerra de baixa intensidade}

A guerra de baixa intensidade é um tipo de confronto político-militar fora dos padrões da guerra convencional e que passa por cima da competência de estabelecer vias pacíficas de resolução de conflito entre as partes. A GBI envolve frequentemente prolongadas lutas de princípios e ideologias, se desenvolvendo através de uma combinação de recursos políticos, econômicos, de informação e militares. Entre vários fatores que são requisitos fundamentais para efetivar operações de GBI, um deles é a adaptabilidade. O exército mexicano, a princípio, haveria respondido esse critério satisfatoriamente:

[...] The Chiapas experience indicates that the Mexican military is capable of doctrinal and organizational innovation. A range of positive changes (a move to smaller units, to decentralized tactical control, etc.) should serve as force multipliers and modifiers for the 130,000-man Mexican army, allowing it to wage counternetwar on multiple fronts (RONFELDT et al, 1998, p. 107).

Nesse contexto e a partir dessa perspectiva, se entende claramente como é que o levantamento do Exército Zapatista de Liberação Nacional (EZLN) em Chiapas, uma rebelião insurgente de uns poucos milhares de indígenas camponeses atentou diretamente contra os interesses dos EUA. Toda essa engenharia militar não se deve apenas a um afã belicista injustificado. Não devemos esquecer que Chiapas é uma região muito rica em recursos naturais, muitos deles ainda inexplorados industrial e comercialmente em grande escala, pela proteção que vigorava desde o governo de Lázaro Cárdenas (1940) até a mudança constitucional do Art. 27 efetivada por Calos Salinas de Gortari (1992). 
Então, como já comentamos, entre o dia $1^{\circ}$ e o dia 12 de janeiro de 1994, a guerra contra as/os Zapatistas foi mais um ensaio de guerra de alta intensidade (GAI), como a que orienta a doutrina da guerra contrainsurgente. Mas, a partir de fevereiro de 1995, já no governo de Ernesto Zedillo (1994 - 2000), começa a execução das táticas e estratégias próprias da GBI (FAJARDO CAMACHO, 2011, p. 60; CDHFBC, 1999).

Frequentemente, as operações de contraguerrilha recomendavam manter uma presença expressiva das forças, seja para autodefesa, seja para estar pronto para buscar e destruir missões. Mas, o exército mexicano tomou outro rumo, criando unidades operacionais muito menores, com pelotões compostos de 36 a 45 tropas, com um oficial no comando, implantadas de forma dispersa em toda Chiapas, com o objetivo de dissuadir novos surtos de combate. A melhora nos equipamentos de comunicação e ligações facilitou essa mudança para unidades menores (RONFELDT et al., 1998, p. 74, 77). Essa reestruturação das tropas continua a permitir efeitos psicológicos imediatos para dissuadir ao inimigo, através: a) da ameaça do uso da força, mas sem combater; b) do emprego da força, sem combater, mas em permanente realização de manobras militares sob a hipótese de enfrentamento; c) do uso da força em rápidos ataques localizados, pontuais.

\subsection{O aspecto comunicacional-midiático da guerra de baixa intensidade}

Além da reconfiguração física e técnico-tecnológica do exército federal e dos efeitos psicológicos que dessa presença ostensiva ${ }^{5}$ se desprendem, há outro recurso que é de fundamental importância na GBI para atingir o equilíbrio psicológico-emocional e moral do inimigo: a mídia. Os dados a serem informados podem até ser objetivos, mas seu uso nunca é neutro, ao ponto que em muitos casos chega a gerar uma realidade paralela

\footnotetext{
${ }^{5}$ Segundo o Centro de Derechos Humanos Fray Bartolomé de las Casas (CDHFBC), antes de fevereiro de 1995 havia 13 acampamentos militares em Chiapas, em junho de 1996 já eram 44 e em 1999 a soma ascendia a 83 (cf. op. cit., p. 2). O Centro de Investigación Económica y Política y Acción Comunitaria en Chiapas (CIEPAC) confirma essas informações. Ver Cisneros (2014, Anexo - Mapas, Figura 14). A pesquisa de Gloria Muñoz Ramírez (2003) revela que segundo dados levantados por diversas organizações indígenas e sociais de Chiapas, não zapatistas e até dissidentes, em 1999 havia 266 posições militares do exército federal em Chiapas, quando em 1995 eram 76 postos (Ibid, p. 175).
} 
completamente diferente dos fatos que estão acontecendo. Isso faz com que a mídia se converta em oficialista ou, pelo menos, discricionária. É claro que esse fenômeno não acontece só no México, pois sabemos que os grupos midiáticos são monopólios e oligopólios transnacionais. No caso do conflito zapatista, chegamos a apreciar uma verdadeira manipulação e distorção dos acontecimentos. Para exemplificar isso, basta apreciar apenas um exemplo, apenas um episódio dessa (des)informação que surge se confrontamos a versão de Héctor Aguilar Camín (2007) na Revista Nexos (México) sobre os acontecimentos de dezembro de 1997, conhecidos como O Massacre de Acteal, com a análise de Ronfeldt et al (1998). Nem é preciso contrapor a versão de Aguilar Camín à versão de um jornal que é solidário com a causa zapatista como é La Jornada (México), nem com a própria Radio Insurgente ou a revista Rebeldía, veículos de comunicação das/os Zapatistas. A discrepância entre as leituras de Aguilar Camín e Ronfeldt et al sobre o que ali aconteceu é tão grande, que deixa perplexo a qualquer um.

Os textos de Aguilar Camín se inscrevem perfeitamente dentro da lógica da GBI, que consiste em confundir a opinião pública fazendo uso de um dos recursos mais comuns, isto é, apelar para um esquema de análise semelhante ao que apreciamos em telenovelas. Ou seja, queremos dizer que, apesar da rica profusão de dados e detalhes secundários e folclóricos, e apesar da habilidade do estilismo literário, tudo isso não passa de enfeites de um esquema excessivamente simplificado e caricaturesco para analisar as relações e os sentimentos humanos. Isso leva o/a leitor/a inevitavelmente à conclusão de que em Acteal não aconteceu mais do que outro caso de confronto entre baixas paixões, egoísmos e mesquinharias próprias do ser humano, que tomaram conta das pessoas e transbordaram em excessos. Em termos políticos, isso se traduz em que o conflito, mesmo tendo sido uma chacina, Acteal não vai além de um simples e isolado conflito intercomunitário, interétnico e/ou religiosos, como tantos outros corriqueiros entre índios. Isso, quando a própria pesquisa dos serviços de inteligência estadunidenses confirma que o que aconteceu foi que "for a mixture of reasons, local paramilitar gunmen loosely affiliated with the PRI massacred a number of villagers, some of whom were EZLN sympathizers" (RONFELDT et al, 1998, p. 83) ${ }^{6}$. Ou seja, claramente um massacre

\footnotetext{
${ }^{6}$ Ver também Idem, p. 4, 81, 82, 87, 108 e 111.
} 
perpetrado por pistoleiros e paramilitares, versão que, apesar de não coincidir completamente com a do EZLN, curiosamente, é coincidente nesse ponto da interpretação. Ou seja, não foi uma simples rixa interna das comunidades, motivada por interesses mesquinhos, como a grande mídia fez parecer.

Citamos aquela tragédia só como um exemplo, de fato, um dos mais escandalosos nessa questão do uso da (des)informação como apetrecho de guerra. Mas isso é um tipo de ação regular que se repete diariamente em meios gráficos e televisivos ${ }^{7}$. Nessa distorção dos acontecidos e manipulação da opinião pública, não estão isentos os grandes grupos midiáticos, como foi o caso do grupo Televisa, que tem sido alvo de protestos políticos públicos, questionando seu trabalho jornalístico de (des)informação.

\subsection{O pacto cívico-militar para a guerra de baixa intensidade}

Para os fins deste texto, gostaríamos de destacar mais um fator-chave implementado com grande sucesso e muita eficiência dentro da GBI no conflito políticomilitar em Chiapas: a ação de grupos paramilitares, que contam com financiamento, equipamento e treinamento do governo estadual e federal. Essas pessoas moram dentro ou perto das comunidades organizadas que contrariam as políticas do governo. A partir do conflito de 1994, seu objetivo tem sido o de deslocar a população e destruir as Bases de Apoio Zapatistas (BAZ). A essas organizações o Estado delega o cumprimento de missões que as forças armadas regulares não podem levar a cabo abertamente. Embora esses grupos sejam, considerados ilegais, ainda assim "la palavra paramilitar no aparece como delito en el Código Penal ni Federal ni estatal" (CDHFBC, 1999, p. 13) ${ }^{8}$, agem impunemente sob a tutela do Estado, segundo convenha aos interesses do governo de turno. Como já citamos no exemplo do Massacre de Acteal, essa estratégia tem permitido ao governo apresentar a guerra contra as/os Zapatistas perante a mídia como simples e

\footnotetext{
7 É claro que isso não se limita só ao México, porque, por um lado, sabemos que as grandes corporações de notícias são monopólios e oligopólios com participação de capitais transnacionais e, por outro, porque redes semelhantes em outros países também apresentam essa versão dos fatos.

${ }^{8} \mathrm{O}$ CDHFBC (Idem) informa que o que sim aparece legalmente como delito é portar, traficar, comprar e vender armas, assim como constituir associação delituosa.
} 
isolados conflitos intercomunitários e/ou religiosos. Por exemplo, quando o governo propõe algum projeto de desenvolvimento e esse é resistido pelas/os Zapatistas, os paramilitares se apresentam como uma força civil que apoia tais iniciativas, gerando conflitos internos, para os quais se solicita a intervenção do governo municipal ou estadual como mediador. Resumidamente, o paramilitarismo serve para fins de contrainsurgência, destruindo ou deteriorando o tecido social que supostamente apoia a guerrilha. Age sob as mais diversas expressões, por exemplo, agredindo os prestadores de serviços sociais em acampamentos de refugiados; originando condições para a expulsão e deslocamento de comunidades indígenas e camponesas; se coligando com autoridades civis; acossando mediante o acionar de juízes venais e as policias; infiltrando associações religiosas, realizando trabalhos de inteligência; apoiando propostas desenvolvimentistas que frisam o suposto benefício social, mas sem questionar a deterioração ambiental que geram; caracterizando como inimigos do desenvolvimento as comunidades que se recusem a se submeter à lógica do capital e, sobretudo, contribuindo fortemente para o aumento da espiral de violência nas comunidades (FAJARDO CAMACHO, 2011, p. 60-61).

Um documento de 1999, baseado nas comunicações e denúncias de várias pessoas e/ou entidades que moram nas regiões Norte, Selva e Altos em Chiapas, afirma o seguinte:

[...] Del universo total de Documentos, los emisores registran 64 actores distintos agresores. Los emisores responsabilizan como Agresores a los siguientes sectores, por orden de importancia: Gobierno 38\%, Paramilitares $17 \%$, Partidos Políticos 16\%, Ejército Mexicano 15\%, Autoridades Municipales 6\%, Sociedad Civil 3\%, EZLN, 3\%, Organizaciones Sociales 2\% e Iniciativa Privada 1\% (HIDALGO; CASTRO, 1999). Grifos nossos.

Como podemos apreciar, não existe um único agressor contra as comunidades zapatistas ou simpatizantes desse projeto sócio-político-cultural. Isto nos permite esclarecer um ponto de grande importância para melhor nos aproximarmos dessa realidade. 
Até agora, entre os protagonistas que combatem o Zapatismo, só mencionamos o exército federal, o exército estadunidense (como assessor da inteligência militar) e os paramilitares. Mas, convém que façamos duas observações. Primeiramente, quando falarmos em exército, não é apenas essa força que age isolada, pois a ela se somam, se articulam e coligam estrategicamente o exército propriamente, mas também a força aérea, junto às forças policiais (Policia Judicial Estatal e Policia Federal Preventiva). Por outro lado, quando falamos em paramilitares, devemos diferenciar entre três grupos civis armados diferentes: paramilitares propriamente, guardias blancas e pistoleiros. Esses últimos são pessoas contratadas por latifundiários e fazendeiros como guardas para sua segurança pessoal, da sua família e sua propriedade. As guardias blancas são grupos de pistoleiros contratados por várias famílias de fazendeiros e latifundiários para agirem a nível regional ou estadual. Esses grupos têm se mostrado úteis para expulsar camponeses das terras por via da violência e garantir a posse delas para aquelas famílias que os contrataram. O escopo do agir das guardias blancas não se limita às/aos Zapatistas, nem aos indígenas, nem sequer aos camponeses, pois servem para hostilizar, ameaçar, amedrontar etc. a qualquer outro grupo rival dessas famílias. Finalmente, os paramilitares são grupos recrutados, treinados, organizados e protegidos pelo exército e corporações policiais, cujo objetivo é o de ameaçar, atacar e até assassinar grupos e organizações que sejam opositores ao governo, é claro, especialmente as/os insurgentes e as BAZ (CDHFBC, 1999) $)^{9}$

A seguir, apresentamos um quadro que facilitará para ter uma visão de conjunto dos elementos que se articulam para desenvolver a GBI em Chiapas. É importante destacar que essa informação, a tomamos de um folheto elaborado pelo CDHFBC $(1999)^{10}$, com a finalidade de que circulasse entre a população, para que se informasse e, sobretudo, que soubesse o que fazer para se proteger. Outro dado importante é que essas informações foram sistematizadas a partir da perspectiva de quem padece essa

\footnotetext{
${ }^{9}$ Ver Cisneros (2014, Anexo - Mapas, Figuras 12 e 13), para ter um panorama dos grupos armados e paramilitares ativos até 1998 e suas áreas de influência.

${ }^{10} \mathrm{O}$ Centro de Derechos Humanos Fray Bartolomé de las Casas é uma ONG cujo objetivo é a promoção e defesa dos direitos humanos, criada pela Diocese de San Cristóbal de las Casas, sendo seu presidente o bispo Don Samuel Ruiz García.
} 
realidade, em muitos casos, sem ter qualquer tipo de responsabilidade ou vínculo com os grupos rebeldes.

\begin{tabular}{|c|c|c|}
\hline Quem & Objetivos & Ações \\
\hline $\begin{array}{l}\text { Exército Mexicano, } \\
\text { Policía Judicial Estatal, } \\
\text { Instituto Nacional de Migración, } \\
\text { Procuraduría General de la } \\
\text { República, } \\
\text { Policía Federal Preventiva }\end{array}$ & $\begin{array}{l}\text { Provocar terror, } \\
\text { Enganar a população, }\end{array}$ & $\begin{array}{l}\text { Voos a baixa altitude nas comunidades, } \\
\text { Intimidações, batidas em postos de } \\
\text { controle, } \\
\text { Incremento da presença policial e militar } \\
\text { nas comunidades, } \\
\text { Invasões nas casas e detenções } \\
\text { arbitrárias, } \\
\text { Ameaças e expulsão de observadores } \\
\text { estrangeiros e de religiosos da Diocese } \\
\text { de San Cristóbal, } \\
\text { Realização de obras de ação social } \\
\text { (pintam escolas, cortam o cabelo etc.), } \\
\text { Entrega de cestas básicas e de materiais } \\
\text { de construção para famílias que os } \\
\text { apoiam, }\end{array}$ \\
\hline $\begin{array}{l}\text { Instituições de serviços públicos } \\
\text { (Saúde, Educação e programas } \\
\text { específicos) }\end{array}$ & $\begin{array}{l}\text { Enganam e convencem às } \\
\text { pessoas, } \\
\text { Desorientam as pessoas } \\
\text { sobre quais as causas do } \\
\text { conflito e a luta social, }\end{array}$ & $\begin{array}{l}\text { Entrega discricionária de créditos, } \\
\text { materiais de construção, medicamentos, } \\
\text { cestas básicas, salários mínimos para } \\
\text { promotores, } \\
\text { Suspensão de programas que } \\
\text { beneficiavam às comunidades, } \\
\text { Criação de centros de atendimento } \\
\text { social, geridos por funcionários e } \\
\text { militares que terão a função de vigiar e } \\
\text { controlar, } \\
\text { Não cumprimento de promessas que } \\
\text { divide mais ainda a população, } \\
\text { Dão noticias falsas que levam a acreditar } \\
\text { que a intenção do governo é a procura } \\
\text { do bem-estar, escondem a pobreza e } \\
\text { demais problemas que há nas } \\
\text { comunidades, }\end{array}$ \\
\hline Mídia & & $\begin{array}{l}\text { Sobre notícias falsas: IDEM anterior, e } \\
\text { também falam que os dirigentes dos } \\
\text { movimentos sociais são estrangeiros, } \\
\text { falam que os rebeldes são delinquentes, } \\
\text { Não noticiam o que acontece nas } \\
\text { comunidades, }\end{array}$ \\
\hline Grupos paramilitares & $\begin{array}{lccr}\text { Utilizam } & \text { o } & \text { terror } & \text { para } \\
\text { romper o } & \text { apoio } & \text { da } \\
\text { população } & \text { com } & \text { a } \\
\text { insurgência. } & & \end{array}$ & $\begin{array}{l}\text { Ameaçam às pessoas que apoiam à } \\
\text { guerrilha, } \\
\text { Despejam populações para romper os } \\
\text { laços familiares e comunitários. }\end{array}$ \\
\hline
\end{tabular}


Como podemos apreciar, é uma articulação estratégica de instituições militares e políticas de diferentes níveis e graus de abrangência e competência; públicas e privadas. Esse quadro de agentes e ações nos dá uma ideia aproximada da complexidade da GBI.

Cabe sinalizar que essa estratégia-estrutura se alastra para além da região identificada como "zona de conflicto" (LEYVA SOLANO, 2009, p. 118). Isto, possivelmente, graças à leitura da inteligência estadunidense, que analisava da seguinte maneira:

[...] Meanwhile, the dynamics of netwar have diffused to other areas of Mexico and beyond. In 1996 in the state of Guerrero, for example, it diffused first as social netwar with the removal of the governor, following a violent suppression of peasant protesters that aroused the wrath of human-rights NGOs, particularly after a videotape of the incident became public. Then, it diffused as a guerrilla netwar with the emergence of the EPR in Guerrero and elsewhere, an unwelcome development for the EZLN that is discussed next (RONFELDT et al, 1998, p. 88).

Aqui temos um exemplo daquilo para o qual Leyva Solano advertia, ou seja, sobre as consequências concretas práticas diretas sobre a população mexicana a partir de leituras como as que apresentam os agentes do RAND's Arroyo Center. Se vemos com cuidado, da leitura que elas/es fazem, se desprendem as seguintes conclusões: a) a social netwar manifesta uma dinâmica de tipo viral, isto é, se multiplica, se espalha, contamina e mata a vida que atinge; b) sua estrutura é rizomática, isto é, não é uma estrutura hierárquica piramidal, tem ramificações irregulares, está descentralizada em mais de um núcleo ou centro de poder de mando, sendo cada um deles de funcionalidade variável; c) o conflito no Estado de Guerrero não é contemplado na sua própria gênese históricosocial-cultural-política, é simplesmente identificado como se fosse a mesma coisa que o conflito zapatista em Chiapas, aliás, uma ramificação viral deste; d) o exército e demais forças devem agir da mesma maneira que em Chiapas nessas várias frentes simultaneamente. 
O problema é que perante essa leitura, não seria justo nem adequado dizer que é tudo falso, porque não é. Por exemplo, nós mesmos aceitaríamos de bom grado as conclusões "a" e "b". Mas, a nossa discussão se orienta às brutais simplificações, como são as conclusões "c" e "d" por exemplo, que não se percebem como distorções (perversas) da realidade pelos simples fato de serem análises que focam o conflito apenas desde a perspectiva do agir militar orientado para o estabelecimento da ordem e da paz perpétua ${ }^{11}$.

É dessa maneira e a partir dessa perspectiva, que essas orientações se tornam doutrina para a GBI desenvolvida pelo governo e exército mexicanos, habilitando-os para a impune violação dos direitos humanos de populações civis inteiras, sem diferenciar se são combatentes ou não, crianças, idosas/os, doentes ou não, que simplesmente recebem o crachá de inimigos. Dito em outras palavras, isso é a criminalização dos movimentos sociais, que justifica e deixa a via livre para perseguir e, até, aniquilar de maneira política, psicológica, física e cibernética a todo indivíduo e/ou grupo que seja avaliado como potencialmente perigoso para a governabilidade do grupo que hegemoniza o domínio das alavancas do aparato do Estado e do mercado. E aqui é onde radica o perigo da interpretação de Castells analisada por Leyva Solano (2007), porque essa criminalização é possível, entre outros fatores, porque não há uma discriminação conceitual adequada e os movimentos sociais que se organizam em redes sociais e cibernéticas, desde o olhar de quem precisa manter a ordem, entram no mesmo balaio junto a redes de narcotraficantes ou redes do crime organizado. Isto é, não diferenciam entre quem contesta, em reclamo de justiça, liberdade, democracia, ou seja, de dignidade, daqueles que simplesmente violam a lei em prol do lucro e outros benefícios próprios (LEYVA SOLANO, 2009, p. 120).

\footnotetext{
${ }^{11}$ Parece-nos que aqui cabe muito bem a perspicaz ironia de finíssimo humor proposta por Kant (1989), quando escreveu seu livro titulado exatamente assim, À paz perpétua, escrito em 1795, justamente, pensando o problema de uma relação política e pacífica entre as nações.
} 


\subsection{A dissociação entre discurso oficial e ações efetivas de governo para a guerra de baixa intensidade}

Algumas das formas concretas em que essa estratégia da GBI é implementada pelo governo mexicano em Chiapas é através do gritante e cínico divórcio entre discurso público e o agir efetivo para a resolução do conflito. Essa tática concreta foi amadurecida ao longo de 1994, quando o resultado foi que aquele único ataque enérgico e maciço não acabou com o EZLN. Pior ainda, por um lado, nem as novas estratégias que começaram a ser desenvolvidas, não só não acabaram com a guerrilha e sua rede social local, como cresceram e se fortaleceram as redes com organizações e instituições de diversa natureza, diferentes trajetórias e históricos, mas que todas coincidiam num ponto: assumir como próprias as bandeiras do EZLN e se articular em redes de solidariedade e resistência. Por outro lado, o governo de Salinas de Gortari e o Partido de la Revolución Institucional (PRI) fecharam esse primeiro ano de confronto com um balanço muito negativo da opinião pública.

Não é por acaso que na gestão de Zedillo (1994 - 2000) serão implementadas de forma drástica todas as opções possíveis para estruturar a mais eficiente GBI. Uma delas será exatamente a de manifestar certa pretensa atitude e vontade no discurso público, mas não acompanhando ou, até contrariando o dito, nos feitos. Um perfeito exemplo disso foi a suposta intenção de diálogo manifesta por Zedillo numa troca epistolar que ele mesmo iniciou em setembro de 1994 endereçada ao EZLN.

Embora céticas/os, as/os Zapatistas concordaram em dar uma chance a essa suposta atitude da presidência da república de dar início a um processo de negociação para resolver de maneira política e pacífica o conflito. Em carta datada em 15 de setembro de 1994, Ernesto Zedillo dizia assim ao EZLN:

[...] La única solución real y justa será la que provenga del diálogo y la negociación [...] la solución tiene que ir al fondo de los problemas sociales y de justicia [...] ustedes tienen que ser parte activa de la solución. La corresponsabilidad será importante no únicamente para la concepción de las soluciones, sino también para su ejecución [...] Debe construirse la confianza y el respeto mutuos, sin exigir el sacrificio de las 
divergencias. Así, debe privilegiarse la seriedad y la solidez de las negociaciones (CEE; SIPRO 1995, p. 213). Grifos meus.

De fato, ainda que de maneira insuficiente, se estabeleceram as condições que desdobrariam no que foi conhecido como o Diálogo de San Andrés ${ }^{12}$, dando lugar à assinatura dos primeiros acordos de paz em base a debates e documentos conjuntos entre o EZLN e o governo, junto aos seus convidados e assessores, conhecidos como os Acordos de San Andrés, assinados em 16 de fevereiro de 1996. A partir desses documentos, de 24 a 29 de novembro de 1996 se reuniram o EZLN, a Comisión de Concordia y Pacificación (COCOPA) e a Comisión Nacional de Intermediación (CONAI) para elaborar e aprovar uma proposta de lei de reforma constitucional sobre Direitos e Cultura Indígena que, embora não respondesse completamente às expectativas das/os Zapatistas, foi aceita pelas/os rebeldes como uma demonstração de disposição autêntica para a negociação e o diálogo, apostando numa possibilidade de continuar progredindo nessa direção. Logo depois, os deputados e senadores envolvidos nesse processo se reuniram com o presidente Zedillo para pressionar para que aprovasse essa iniciativa de lei. Ao qual, o presidente respondeu solicitando quinze dias de prazo para responder e, cumprido o mesmo, sua resposta foi “não" (MUÑOZ RAMÍREZ, 2003, p. 128-129). Com isso, o presidente deu um golpe mortal ao processo de diálogo de dois longos e frutíferos anos, exemplares para a democracia do país e o mundo. Ao mesmo tempo, confirmou todos os receios, desconfianças e dúvidas das/os indígenas zapatistas (e não zapatistas), justificadas por mais de quinhentos anos disso mesmo: desprezo, desrespeito, engano, trapaça, autoritarismo, violência, dominação. Essa atitude também foi só mais um exemplo de que a palavra empenhada do governo não tem valor ético-político algum, quando se contradiz a si mesma tão descarada e impunemente.

O governo Zedillo introduziu reformas à proposta apresentada pelos legisladores da COCOPA, que em 11 de janeiro de 1997 foram rejeitadas pelo EZLN, com o qual também anunciaram sua retirada das mesas de negociações até que o acordado em San Andrés

\footnotetext{
${ }^{12}$ Esse nome deriva do povoado San Andrés Sacamch'en de los Pobres, que se estabeleceu como sede para a conformação das mesas de diálogo conjunto entre o governo e o EZLN. Ver Cisneros (2014, Anexo Mapas, Figura 15).
} 
fosse cumprido. Ao qual, o governo respondeu com mais presença militar e mais hostilizações e assédio às comunidades (MUÑOZ RAMÍREZ, 2003, p. 131).

Essa atitude de não negociar e impor de forma autoritária e verticalmente uma lei significou o completo e absoluto desconhecimento de todo um intenso e longo processo de diálogo e negociação que houve entre as comunidades de diferentes etnias, as diferentes associações indígenas e sociais, intelectuais, personalidades das artes e da cultura, políticos, a sociedade civil e os governos estadual e federal. Um fato inédito na história do país. Mas essa posição será confirmada não apenas pelo Poder Executivo da Nação, como também pelo Poder Legislativo, quando em 25 de abril de 2001 o Senado da República aprovou por unanimidade a reforma constitucional em relação a questões indígenas. A mesma posição será manifesta pelo Poder Judiciário, quando em 6 de setembro de 2002 a Suprema Corte de Justiça da Nação declarou improcedentes 322 das 330 objeções constitucionais apresentadas por 330 municípios dos estados de Chiapas, Guerrero, Hidalgo Jalisco, Michoacán, Morelos, Oaxaca, Puebla, Tabasco e Veracruz, em contra do procedimento empregado para aprovar essas reformas constitucionais em relação a questões de direitos e cultura indígenas (Ibid, p. 206 e 219).

Como podemos observar, não foram só os três poderes da república que optam por não dar ouvidos à população, nem só o Partido da Revolución Institucional (PRI), como também o Partido Acción Nacional (PAN) na gestão de Vicente Fox (2000 - 2006). Esse fato é uma clara amostra da GBI, especialmente na sua alternativa de uso da palavra para confundir, desinformar, fingir, enganar, afirmando que a situação é e será de um jeito, enquanto as ações vão em direção exatamente oposta, sem qualquer vínculo ou compromisso.

Outro exemplo de manobra dentro da estratégia da GBI em Chiapas é a de desenvolver programas de governo sob a fachada de reformas políticas que irão beneficiar o amadurecimento e melhor desenvolvimento da democracia, quando o que se procura é minar, obstaculizar, impossibilitar, atrapalhar e sabotar o desenvolvimento dos Municípios Autônomos Zapatistas (MAREZ). 
Aqui, nos apoiamos na pesquisa desenvolvida e coordenada por Leyva Solano e Burguete Cal (2007), cuja tese central afirma que o projeto de remunicipalização ${ }^{13}$ proposto e desenvolvido parcialmente pelo governador interino de Chiapas, Roberto Albores Guillén (1998 - 2000) em 1998, é um programa de reordenação político-territorial, que não passaria de ser um medíocre exercício burocrático-administrativo, se não fosse porque acontece dentro de condições de GBI e pelas implicações existenciais para milhares de pessoas afetadas ${ }^{14}$.

Resumidamente, a proposta de Albores consistia na criação de 33 municípios, afetando principalmente a chamada zona de conflito, o qual se traduziria na incorporação automática e vertical dos municípios autônomos zapatistas (o qual nunca aconteceu nos fatos). Assim, a estratégia de Zedillo-Albores mostra escancaradamente que a remunicipalização, ainda que apresentada como instrumento para a paz, é um instrumento de guerra, como mais um dos mecanismos não convencionais de guerra utilizados no conflito político-militar em Chiapas, orientados a desarticular e aniquilar zapatistas e pró-zapatistas, através de estratégias econômicas, políticas, psicológicas e militares.

Considerando só uma das arestas dessa guerra, ou seja, a dimensão política da contrainsurgência, a proposta Albores-Zedillo se entende de maneira muito coerente como mais uma ação dentro do marco da guerra de redes sociais, para revidar o avanço e consolidação dos MAREZ, que em 1997-1998 eram a peça-chave da estratégia política internacional do EZLN. Essa proposta é o avanço de um mecanismo governamental de controle do território, de recursos e de pessoas, ao mesmo tempo em que continua de maneira robusta e homogênea a militarização e paramilitarização de Chiapas. Até onde se sabe, pesquisas feitas em campo sugerem que "para fines de 1999 había 655 puntos geográficos policíaco-militares y aproximadamente de 70 mil a 80 mil efectivos presentes,

\footnotetext{
13 A primeira proposta nessa matéria foi feita em 1994 pelo Primero Comisionado para la Paz y la Reconciliación en Chiapas, Manuel Camacho Solís, para criar novos municípios, que o EZLN rejeitou, por entender que era uma estratégia para distrair a atenção da demanda central das/os Zapatistas, isto é: o reconhecimento constitucional da autonomia e a livre determinação dos povos indígenas. (Idem, p. 23 e 26).

${ }^{14}$ Além do mais, também não respeita os Acordos de San Andrés de 1996 (Idem, p. 25-26).
} 
cuando el gobierno acepta sólo entre 17 y 25 mil [...] [e] 12 grupos paramilitares" (LEYVA SOLANO; BURGUETE CAL, 2007, p. 13 e 32$)^{15}$. Ainda que o governo nunca tenha admitido a existência desses grupos paramilitares, no máximo, com dificuldade tem admitido a existência de civis armados, mas não grupos organizados nem treinados profissionalmente.

\subsection{Políticas de "preservação ambiental" para a guerra de baixa intensidade}

Outra manobra que se desenvolve como parte dessa GBI em Chiapas para o controle de áreas ricas em recursos naturais, habitadas por povos indígenas é a de declarar Áreas Naturales Protegidas (ANP) sem consultar as comunidades, como é o caso da reserva de Montes Azules ${ }^{16}$ (FAJARDO CAMACHO, 2011, p. 38-43). Essa iniciativa, a princípio tão cara a vários setores sociais e organizações políticas, no fundo, não passa de outra arma política ${ }^{17}$ de controle e domínio discricionário da terra, que se traduz em ameaças, hostilizações, agressões e despejos de comunidades inteiras, sob o amparo da lei e em prol da proteção do meio ambiente. Vemos, assim, que os objetivos centrais continuam a ser aqueles mesmos identificados na remunicipalização de Albores.

Nessa mesma direção caminham as ações governamentais com a promoção de projetos turísticos sob o argumento do desenvolvimento econômico-social e a geração de emprego. Contudo, objetivos mais fundamentais se encobrem por trás deles, quais sejam, o controle sobre a terra e os recursos, poder negociar isso com empresas privadas, ter desculpa para atropelar as comunidades indígenas improdutivas e, especialmente, os MAREZ e as BAZ. Como nos exemplos anteriores, a história se repete: atos violentos, ameaças, golpes, disparos para intimidar, sobrevoos de helicópteros, invasões, despejos,

\footnotetext{
${ }^{15}$ As autoras tomam esses dados de Global Exchange, Centro de Investigaciones Económicas y Politicas de Acción Comunitaria (CIEPAC) e Centro Nacional de Comunicación Social (CENCOS).

${ }^{16}$ Ver Cisneros (2014, Anexo - Mapas, Figura 16).

${ }^{17}$ Essa expressão, a princípio deveria nos provocar algum ruído, por ser um oximoro, mas, o alarmante é o fato de que não causa desconforto. Isto pode significar que no senso comum, no fundo, a política é uma guerra.
} 
etc. amparados no véu da proteção do meio ambiente e o fomento do desenvolvimento econômico-social (Ibid, 44-49).

A pesquisa de Fajardo Camacho (2011) nos apresenta um excelente exemplo de como acontece esse tipo de acionar disfarçado e dissimulado do governo que oferece uma imagem pública de desenvolvimento, paz e progresso, quando a intenção é a de aumentar as áreas de controle (econômico e militar) sobre o território ganho pelas/os Zapatistas, o que se traduz em controle dos recursos naturais para negociar com empresas para negócios de desenvolvimento turístico, dos quais se beneficiarão poucos e pequenos grupos econômicos. De igual maneira, isso significaria controle sobre as populações e fragilização, enfraquecimento das/os Zapatistas e dos MAREZ, para seguir avançando geoestrategicamente na região.

\section{Considerações para o debate}

Esses processos-instrumentos, a partir de uma perspectiva ingênua ou inadvertida são efetivamente instrumentos políticos, mas que vistos criticamente, percebemos que são instrumento de guerra e contrainsurgência dentro de um contexto de GBI e de guerra de redes, assim como são claras manifestações de desprezo e profundo racismo. Por isso, na nossa leitura, essas manobras, vêm diretamente ao encontro da leitura de Foucault, no que ele chama de hipótese de Nietzsche, quando afirma que "a política é a guerra continuada por outros meios", invertendo o aforismo de Clausewitz (FOUCAULT, 2005, p. 22).

Até aqui, uma contextualização, a mais completa possível, das características principais e mais importantes desta guerra que, como já foi dito, vem sendo travada há séculos, só que em $1^{\circ}$ de janeiro de 1994 aconteceu mais um episódio de explicitação escancarada da mesma. É claro que essa pesquisa não tem a ingênua pretensão de apresentar uma caracterização exaustiva dessa guerra, que consiga esgotar todas suas arestas. Este texto apenas traz a preocupação de apresentar um panorama claro, sobretudo, visando o público leitor que não conhece essa realidade. 
Finalmente, também convidar o leitor a refletir sobre a curiosa familiaridade de tais estratégias empregadas pelo que as/os Zapatistas chamam de mau-governo, em outros processos, em outras regiões da América Latina, aliás, no próprio Brasil.

\section{Referências}

AGUILAR CAMÍN, Héctor. Regreso a Acteal I. La fractura. Nexos, México, 7 out., 2007. Disponível em: <http://www.nexos.com.mx/?p=12368>. Acesso em: 9 jan. 2014.

CARTER, James. [Carta. State of the Union Address. The Capitol, Washington, D.C. January 23, 1980]. AIR FORCE Magazine, v. 93, n. 4, abr. 2010. Disponível em: <http://www.airforcemag.com/MagazineArchive/Documents/2010/April202010/0410fullke eper.pdf >. Acesso em: 10 jan. 2014.

CENTRO DE DERECHOS HUMANOS FRAY BARTOLOMÉ DE LAS CASAS (CDHFBC). Los grupos paramilitares en Chiapas. San Cristóbal de las Casas, [1999]. Disponível em: <http://www.frayba.org.mx/archivo/informes/990110_los_grupos_paramilitares_en_chiap as_frayba.pdf $>$. Acesso em: 7 jan. 2014.

CENTRO DE ESTUDIOS ECUMÉNICOS (CEE); SERVICIOS INFORMATIVOS PROCESADOS, A.C. (SIPRO). Cartas entre Ernesto Zedillo y el EZLN. In: . Los hombres sin rostro II. Dossier sobre Chiapas. México: CEE; SIPRO, 1995.

CISNEROS, Leandro Marcelo. Guerra e política nas comunidades zapatistas de ChiapasMéxico: resistência e criação. 2014. 933 p. Tese (Doutorado) - Universidade Federal de Santa Catarina, Centro de Filosofia e Ciências Humanas, Programa de Pós-Graduação em Ciências Humanas, Florianópolis, 2014.

FAJARDO CAMACHO, Andrea. La guerra por los "recursos naturales" en el capitalismo neoliberal y la Reserva Comunitaria Zapatista El Huitepec. Un análisis en camino a la descolonialidad. 2011. Trabalho de Conclusão de Curso (Bacharelado em Antropologia) Universidad Veracruzana, Facultad de Antropología. Xalapa, Veracruz, 2011. Disponível em: <http://zapatismoyautonomia.files.wordpress.com/2012/01/tesis-andrea-fajardocamacho.pdf >. Acesso em: 22 dez. 2013.

FOUCAULT, Michel. Em defesa da sociedade: curso no Collège de France (1975-1976). São Paulo: Martins Fontes, 2005.

HIDALGO, Onécimo; CASTRO, Gustavo. La estrategia de guerra en Chiapas. CIEPAC, San Cristóbal de Las Casas, Chiapas, 10ut. 1999. Disponível em:

<http://www.ciepac.org/documento.php?id=67>. Acesso em: 9 jan. 2014. 
LEYVA SOLANO, Xóchitl. Identidades políticas y redes de movimientos sociales e la Era de la información. El neozapatismo como estudio de caso. Revista Voces, Guatemala, n. 1, p. 77-100, jun. 2007.

LEYVA SOLANO, Xóchitl. Nuevos procesos sociales y políticos en América Latina. In. HOETMER, Raphael (Coord.). Repensar la política desde América Latina: política, cultura, democracia radical y movimientos sociales. Lima: Programa Democracia y Transformación Globa. 2009, p. 109-130.

LEYVA SOLANO, Xochitl; BURGUETE CAL, Araceli (Coord.). La remunicipalización en Chiapas: la política y lo político en tiempos de contrainsurgencia. México, D.F.: CIESAS, 2007, p. 7-43.

LOZANO, Lucrecia; BENÍTEZ MANAUT, Raúl. De la contención pasiva a la guerra de baja intensidad en Nicaragua. Cuadernos Políticos, n. 47, México, D.F.: editorial Era, julioseptiembre de 1986, p. 75-88. Disponível em:

<http://www.cuadernospoliticos.unam.mx/cuadernos/contenido/CP.47/CP47.7.LucreciaLo zano.pdf $>$. Acesso em: 9 jan. 2014.

MARCOS, Subcomandante Insurgente. 7 piezas sueltas del rompecabezas mundial (EI neoliberalismo como rompecabezas: la inútil unidad mundial que fragmenta y destruye naciones.). Cartas y comunicados del EZLN, México, jun. 1997. Disponível em:

<http://palabra.ezln.org.mx/comunicados/1997/1997_06_b.htm>. Acesso em: 19 out. 2013.

MONROY GÓMEZ, Mario; CUENCA, Mary. Cronología sobre los acontecimientos de Chiapas correspondiente a los meses de enero a abril de 1994. In: SIPRO. Los hombres sin rostro I. Dossier sobre Chiapas. México: SIPRO, p. 9-58, 1994.

MUÑOZ RAMÍREZ, Gloria. EZLN: 20 y 10, el fuego y la palabra. México, D.F.: Revista Rebeldía y La Jornada Ediciones, 2003.

RONFELDT, David et al. The Zapatistas Social Netwar in México. Santa Monica, CA: RAND, 1998. Disponível em:

<http://www.rand.org/content/dam/rand/pubs/monograph_reports/1998/MR994.pdf>. Acesso em: 6 jan. 2014.

SCHIAVONE, Patricia Kreibohm de. La doctrina de la Guerra de Baja Intensidad: del intervensionismo norteamericano a la formulación de una nueva categoría de conflicto. Revista Electrónica de Relaciones Internacionales (REDRI), abr. 2003. Disponível em: $<$ http://www.redri.org/Archivos_articulos/guerra\%20baja\%20intensidad-kreibohm.pdf>. Acesso em: 10 jan. 2014. 
UNITED STATES OF AMERICA. ARMY-AIR FORCE CENTER FOR LOW INTENSITY CONFLICT LANGLEY AFB VA. Joint Low-Intensity Conflict Project Final Report. Volume 1. Analytical Review of Low-Intensity Conflict. Fort Monroe, Virginia: Joint Low-Intensity Conflict Project - United States Army Training And Doctrine Command, 01 Aug. 1986. Disponível em:

<http://oai.dtic.mil/oai/oai?verb=getRecord\&metadataPrefix=html\&identifier=ADA185971 >. Acesso em: 12 jan. 2014.

Recebido em: 20/08/2015 Aprovado em: 27/01/2016

Universidade do Estado de Santa Catarina - UDESC Centro de Ciências Humanas e da Educação - FAED

Revista PerCursos Volume 16 - Número 32 - Ano 2015 revistapercursos@gmail.com 